\title{
Second Annual Self-Healing Conference to Be Held in Chicago http://conferences.beckman.uiuc.edu/ICSHM2009
}

The Second International Conference on Self-Healing Materials will be held on June 28-July 1, 2009, in Chicago. The conference will encompass various classes of self-healing materials, including polymers, ceramics, metals, and composites, while biomaterials and bio-inspiration serve as model systems that guide research in the emergent field of selfhealing. The conference is chaired by Scott White of the Beckman Institute within the University of Illinois at Urbana-Champaign and Ian Bond from the University of Bristol in England. The conference is endorsed by the Materials Research Society.

The conference will feature general topics and special symposia. General topics include areas such as self-healing polymers, microvascular systems, and selfhealing coatings and paints, while the special symposia are being organized in a variety of areas, including self-healing supramolecular polymers, numerical analysis tools for self-healing, and mechanochemically active polymers.

The deadline for early fee registration is March 4, 2009.

The first International Conference on Self-Healing Materials was held in the Netherlands in 2007 and included more than 200 researchers from around the world.

\section{The International Integrated Reliability Workshop Held October 2008}

The International Integrated Reliability Workshop (IIRW) was held on October 12-16, 2008 in the Stanford Sierra Camp in California. The workshop, organized by Patrick Lenahan of The Pennsylvania State University and Guoqiao Tao of NXP, offered six tutorials, seven sessions with 24 talks, and a poster session. Workshop attendees came from industry, universities, and research institutes. The workshop focused on ensuring electronic device reliability through fabrication, design, testing, characterization, and simulation, as well as identification of the defects and physical mechanisms responsible for reliability problems.

Subramanyan Dakshinamoorthy of Freescale Semiconductor presented the keynote address on qualification strategies, showing the growing number of complex elements that www.iirw.org

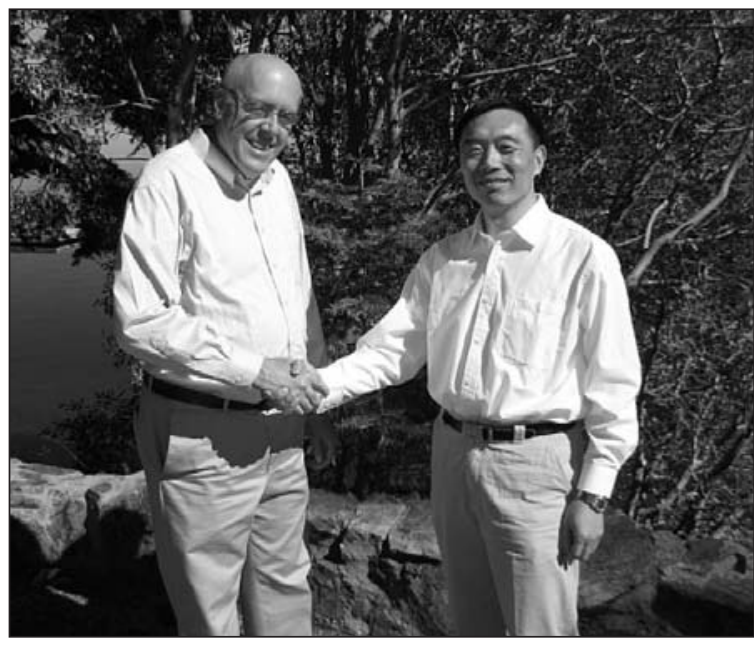

Pat Lenahan (left) of The Pennsylvania State University (Penn State) served as the General Chair and Guogiao Tao of NXP served as the Technical Program Chair of the International Integrated Reliability Workshop.

and automatically compensate for it to avoid any additional reliability guard bands. He said that this circuitry consumes only a small additional space on the respective products. T. Grasser (Technical Univ. of Vienna) gave a tutorial on negative bias temperature instability (NBTI). His reliability simulations and comparison to comprehensive data from the industry have shown that the usually applied reaction-diffusion model cannot describe most of the phenomena observed in NBTI experiments, even with the different corrections to this model that have been proposed throughout recent years.

The majority of the talks given over the following three days concentrated again on NBTI, showing the importance of this degradation mechanism for the microelectronics industry. Other sessions covered backend reliability, reliability of sensors and memories, fast wafer level reliability (fWLR) techniques, reliability of compound materials such as $\mathrm{SiC}$, and high- $k$ reliability work.

Special discussion groups covered NBTI, high- $k$ characterization, and product reliability. The focus on fWLR originated from a Special Interest Group (SIG), initiated by A. Martin (Infineon) during IIRW 2007, to work toward a proposal for fWLR by the Joint Electron Device Engineering Council (JEDEC). Special Interest Groups are a key part of the Reliability Workshop, where scientists can develop collaborations on specific topics.

The final report of IIRW 2008 will include all of the presented papers. The next IIRW will be held at Stanford Sierra Camp, California on October 18-22, 2009.

ROLF GEILENKEUSER Communication Chair 